\title{
1 Atomic force microscopy characterization of polyethylene 2 terephthalate grafting with poly(styrene sulfonate)
}

3 Tuan Ngoc Nguyen ${ }^{1}$; Vincent Humblot ${ }^{2}$; Véronique Migonney ${ }^{{ }^{*}}$; Raphaël Lévy ${ }^{3^{*}}$

$4{ }^{1}$ Laboratory of Chemistry, Structures, Properties of Biomaterials and Therapeutic Agents 5 (CSPBAT), UMR CNRS 7244, Sorbonne Paris Nord University, France

62 Institut FEMTO-ST UMR CNRS 6174, Université Bourgogne Franche-Comté, 15B Avenue des

7 Montboucons, 25030 Besançon, France

$8{ }^{3}$ Université Sorbonne Paris Nord and Université de Paris, INSERM, LVTS, F-75018 Paris,

9 France

Authors

Tuan Ngoc Nguyen: ngoctuan.nguyen@univ-paris13.fr; Vincent Humblot: vincent.humblot@femto-st.fr; Raphaël Lévy: raphael.levy@univ-paris13.fr ; Véronique Migonney: veronique.migonney@univ-paris13.fr

\section{Corresponding Authors}

Prof. Raphaël Lévy (raphael.levy@univ-paris13.fr) Université Sorbonne Paris Nord and Université de Paris, INSERM, LVTS, F-75018 Paris, France

Prof. Véronique Migonney (veronique.migonney@univ-paris13.fr): Laboratory of Chemistry, Structures, Properties of Biomaterials and Therapeutic Agents, Université Sorbonne Paris Nord, 99 Avenue JB Clément, 93430 Villetaneuse, France

\section{Abstract}

Polyethylene terephthalate (PET) is widely used to elaborate biomaterials and medical devices in particular for long-term implant applications but tuning their surface properties remains challenging. We investigate surface functionalization by grafting poly(sodium 4styrene sulfonate, PNaSS) with the aim of enhancing protein adhesion and cellular activity. 
Elucidating the topography and molecular level organization of the modified surfaces is important for understanding and predicting biological activity. In this work, we explore several grafting methods including thermal grafting, thermal grafting in the presence of Mohr's salt, and UV activation. We characterize the different surfaces obtained using atomic force microscopy (AFM), contact angle (CA), and X-ray photoelectron spectroscopy (XPS). We observe an increase in the percentage of sulfur atoms (XPS) that correlates with changes in (CA), and we identify by AFM characteristic features, which we interpret as patches of polymers on the PET surfaces. This work demonstrates tuning of biomaterials surface by functionalization and illustrates the capability of atomic force microscopy to provide insights into the spatial organization of the grafted polymer.

Keywords: Peakforce Quantitative Nano-mechanical Properties (PF-QNM); Polyelectrolyte brushes; Polyethylene Terephthalate (PET), Poly(sodium 4-styrene sulfonate (PNaSS)

\section{Introduction}

Polyesters, in particular polyethylene terephthalate (PET), are used extensively in medical devices. Surface functionalization is often required to improve biological properties. Poly (sodium 4-styrene sulfonate) (PNaSS) is a strong polyelectrolyte, which has been proposed for the control of biological and biophysical properties including enhancing cell adhesion, spreading, and proliferation, thus improving bone tissue response[1,2], fibroblast behavior for reconstructing injured ligament and wound healing[2-5], antibacterial infection[6] and biocompatible surface[5,7]. PNaSS enhances the biological properties of PNaSS-grafted surfaces: the mechanism at the origin of this activity involves specific interactions between adsorbed binding proteins (fibronectin, $\mathrm{FN}$ ) on functionalized surfaces and integrin at the cell membrane[1,2]. Briefly, the presence of sulfonate groups allows improving cell adhesion, proliferation, differentiation and/or biointegration in surrounding tissues when implanted in vivo[1]. This has been shown in vitro with different types of cells (fibroblast, endothelial cell, and osteoblast) and in vivo in the case of PNaSS-grafted titanium, PET and PCL implants. PNaSS immobilized on different materials such as titanium[1,8], polyethylene terephthalate (PET) $[2,3]$, nanoparticle $[5,9,10]$ or polycaprolactone (PCL) has been reported. 
Several surface functionalization methods with poly(styrene sulfonate) have been proposed, e.g. sulfonation polystyrene brush $[10,11]$ and grafting methods[12-14]. Among those, "grafting-from" has the advantage of being a scalable approach to the modification of interfacial properties through immobilizing the functional groups on the substrate by covalent bonding. The "grafting from" method starts with activation of the surface via plasma[15], UV irradiation [7,16], heating[14,18], in the presence of $\mathrm{CuBr}_{2}[18-20]$, or Mohr's salt $[13,14]$.

In this work, we activate PET surfaces by ozonation, a method convenient for materials with complex geometries such as implants[21]. Ozonation generates peroxide groups which decompose upon heating and UV irradiation[14,22,27] to generate radicals on PET; NaSS polymerizes from these active sites. The mechanism can be described as: the peroxides after decomposition form two types of free radicals, ${ }^{\bullet} \mathrm{OH}$ and $\mathrm{O}^{\bullet}$, and then $\mathrm{C}^{\bullet}$ (carbonyl) radicals[21] on the polymer chains. Free radicals ${ }^{\circ} \mathrm{OH}$ can be consumed by $\mathrm{Fe}^{2+}$ in $\mathrm{Mohr}^{\prime}$ s salt, thus reducing homopolymerization and promoting grafting[14,23,24].

Previous studies examined the effect of the graft PNaSS on the interaction of the modified surfaces with biological molecules yet the characterization of the grafted layer is often limited. Here, we investigate the topography of grafted polymers by atomic force microscopy (AFM) complemented by XPS and contact angle measurements.

\section{Materials and Methods}

\subsection{Materials}

Sodium 4- styrene sulfonate (NaSS), phosphate buffer saline (PBS), and Mohr's salt were purchased from Sigma Aldrich. Polyethylene terephthalate (PET) $(0.25 \mathrm{~mm}$, biaxially oriented plate) was purchased from Goodfellow (Paris, France). Ethanol absolute was from Fisher.

\subsubsection{PET preparation:}

PET plate was cut into small squared pieces $(1 \mathrm{~cm} \times 1 \mathrm{~cm})$. The surface was cleaned in an ultrasonic bath with ultrapure water, acetone, and ethanol for $10 \mathrm{~min}$ respectively. The samples were dried under vacuum for $2 \mathrm{~h}$ and stored at $4^{\circ} \mathrm{C}$ until use.

\subsubsection{Monomer purification:}


The purification of NaSS was described $[14,17,25] 90 \mathrm{~g}$ of NaSS was dissolved in $1.6 \mathrm{~L}$ of ethanol: distilled water $(9: 1, \mathrm{v} / \mathrm{v})$ by stirring $12 \mathrm{~h}$ at $70^{\circ} \mathrm{C}$. Thereafter, the solution was filtered by vacuum filtration. The filtered solution was kept at $4^{\circ} \mathrm{C}$ during $24 \mathrm{~h}$ for recrystallization. Recrystallized monomer was collected by vacuum filtration and was dried in vacuum at $30^{\circ} \mathrm{C}$ for $6 \mathrm{~h}$. Finally, the product was kept at $4^{\circ} \mathrm{C}$, away from the light.

\subsection{Functionalization of polyester surfaces by PNaSS ("grafting from")}

\subsubsection{Activating the surfaces by ozonation}

The functionalization of polyesters by PNaSS includes two main steps: ozonation and grafting (Scheme 1). In the first step, the polymer surfaces were activated by ozonation using ozone generator BMT 802N. 6 PET plates were ozonized into $100 \mathrm{~mL}$ distilled water by introducing ozone flow (0.6 bars, $100 \mathrm{~mL} / \mathrm{min}$ ) for $20 \mathrm{~min}$ for PET at $30^{\circ} \mathrm{C}$.[14] Ozonized samples were quickly transferred from the ozonation reactor to the degassed $\mathrm{NaSS}$ solution $(0.7 \mathrm{~mol} / \mathrm{L})$ for grafting.

\subsubsection{Grafting PNaSS from PET substrate}

After activation by ozonation, PNaSS was polymerized from the activated sites (Scheme 1). For determining the influence of ozonation on the surface, non-grafted-ozonized polymer or ozonized PET without grafting was used as a reference. Non-grafted-ozonized PET was prepared by ozonation of a PET plate for $20 \mathrm{~min}$ at $30^{\circ} \mathrm{C}$.

\section{Thermal radical polymerization (method 1 and 2 ):}

Method 1 - Thermal grafting (TG)[13,14]. 6 ozonized PET plates were transferred into $60 \mathrm{~mL}$ of degassed NaSS $(0.7 \mathrm{~mol} / \mathrm{L})$ solution and heated for $1 \mathrm{~h}$ at $75^{\circ} \mathrm{C}$. Peroxide decomposition generates the radicals on the surface for initiating PNaSS polymerization.

Method 2-Thermal grafting in the presence of Mohr's salt (MSG). 6 ozonized PET plates were transferred into $60 \mathrm{~mL}$ degassed mixture solution of NaSS (9 g, $0.7 \mathrm{~mol} / \mathrm{L})$ and Mohr's salt (60 $\mathrm{mg}, 0.1 \%, \mathrm{w} / \mathrm{v}$ ) and heated to $75^{\circ} \mathrm{C}$ for $1 \mathrm{~h}$. Mohr's salt provides $\mathrm{Fe}(\mathrm{II})$ ions that increases significantly the grafting efficiency[14].

\section{Photoinitiated free radical polymerization (method 3):}


Method 3-UV irradiation (UVG)[22]. Peroxides were decomposed by UV irradiation. 6 PET plates were transferred into $60 \mathrm{~mL}$ of degassed NaSS solution $(9 \mathrm{~g}, 0.7 \mathrm{~mol} / \mathrm{L})$. The solution was irradiated by UV light for $30 \mathrm{~min}$ (lamp UV-Omnicure, $254 \mathrm{~nm}, 10 \mathrm{~W} / \mathrm{cm}^{2}$ ) at $25^{\circ} \mathrm{C}$ under stirring.

After polymerization via either of the three methods above, free homopolymer, oligomer, and monomer were removed from the grafted samples under stirring in double distilled water for at least $48 \mathrm{~h}$. The washing solution was tested by UV-vis at $360 \mathrm{~nm}$ to check for the presence of any residue of free PNaSS (homopolymer and oligomer). Samples were finally dried under vacuum and kept at $4{ }^{\circ} \mathrm{C}$, away from the light before use.
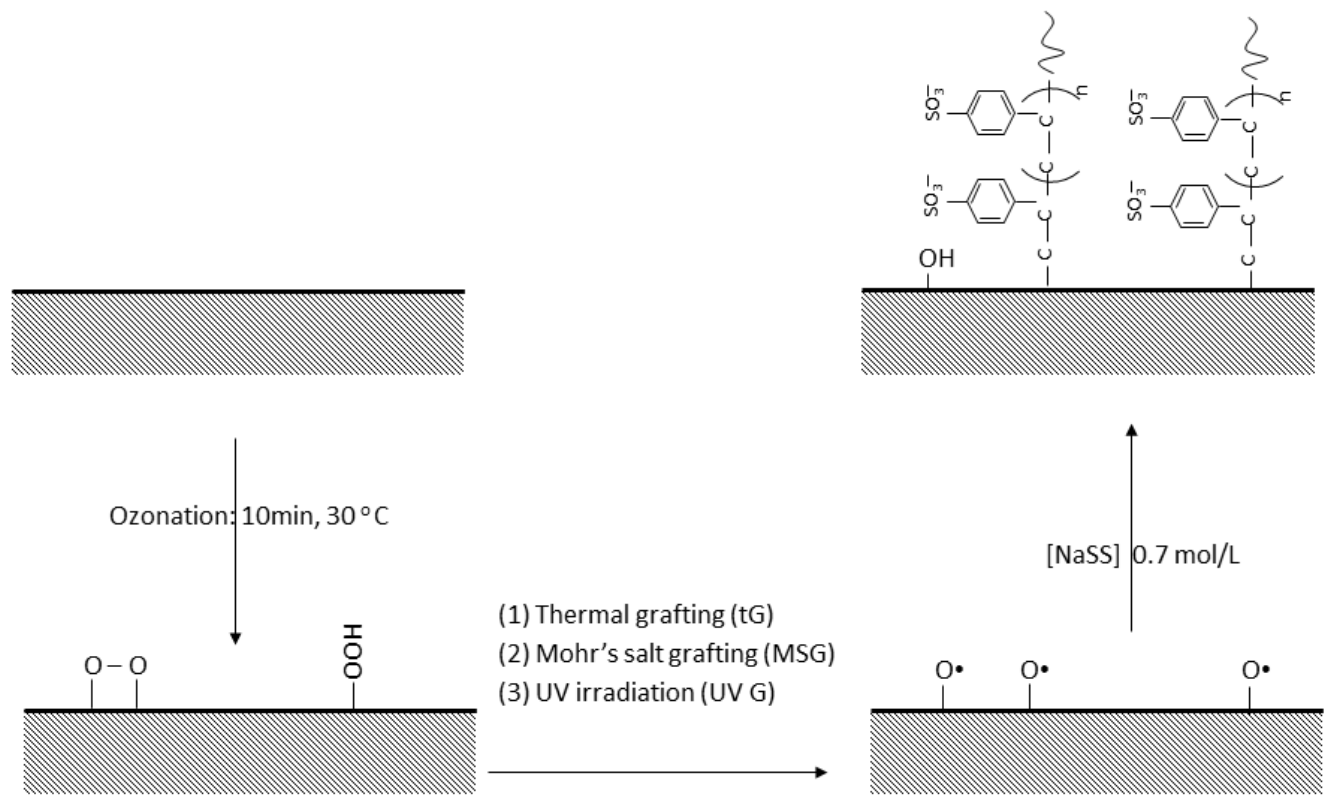

(1) Thermal grafting (tG)

(2) Mohr's salt grafting (MSG)

(3) UV irradiation (UV G)

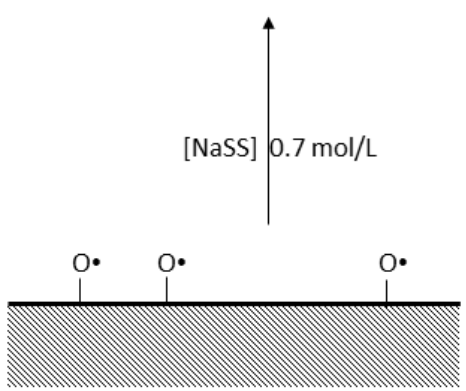

\subsection{Surface characterization}

X-ray photoelectron spectroscopy analysis (XPS). X-ray photoelectron spectroscopy analysis (XPS) (from Omicron Argus spectrometer, Germany) was performed using a monochromated AlKa radiation source $(h v=1486.6 \mathrm{eV})$ working at an electron beam power of $300 \mathrm{~W}$ with $90^{\circ}$ of takeoff angle of photoelectrons emission, under ultra-high vacuum ( $\leq 10^{-10}$ Torr). Spectra were recorded at pass energy of $100 \mathrm{eV}$ for the survey spectrum and pass energy of $20 \mathrm{eV}$ for the high-resolution regions. Binding energies were calibrated against the $\mathrm{C} 1 \mathrm{~s}$ binding energy 
of aliphatic carbon atoms at $284.8 \mathrm{eV}$. Spectral deconvolution was carried out using Casa XPS v.2.3.15 software (Casa Software Ldt, UK). All samples were dry films.

The equivalent thickness probed by XPS is estimated to be close to $3 \lambda=10 \mathrm{~nm}$ representing $95 \%$ of the signal, $\lambda$ being the inelastic mean free path of electrons from the PET substrate in the organic PNaSS film; for electrons having a kinetic energy around $1200 \mathrm{eV}$ (from the C1s atomic level), $\lambda$ is estimated to be equal to $3.23 \mathrm{~nm} .^{1}$

The estimated thickness $(d)$ of PNaSS on top of PET can then be calculated using the following formula:

$$
\frac{I_{S 2 p}}{I_{C 1 s 284 \mathrm{eV}}}=\frac{\rho_{P N a S S} M_{E T} \sigma_{S 2 p} T_{S 2 p} \lambda_{S 2 p}^{P N a S S}\left(1-\exp \left(\frac{-d}{\lambda_{S 2 p}^{\text {PNaSS }} \sin (\theta)}\right)\right)}{\rho_{P E T} M_{N a S S} \sigma_{C 1 s} T_{C 1 s} \lambda_{C 1 S}^{P E T}\left(\frac{-d}{\lambda_{C 1 S}^{\text {PNaSS }} \sin (\theta)}\right)}
$$

Wherein: $\theta$ is the photoelectron collection angle. TC1s and TS2p are the relative sensitivity factors of $C$ and $S$, respectively, provided by the spectrometer manufacturer. The Scofield photoionization cross-sections $\sigma$ are equal to 1 for $C 1$ s and 1.44 for $S 2 p .^{2} \lambda x y$ is the inelastic mean free paths of electrons $x$ in the matrix $y$. They were calculated using the Quases program (QUASES-IMFP-TPP2M Ver.3.0) based on the TPP2M formula. $\rho$ PNaSS and $\rho$ PET are the density of PNaSS and PET, respectively. $\mathrm{M}_{\mathrm{NaSS}}$ and $\mathrm{M}_{\mathrm{ET}}$ are the molecular weight of NaSS (sodium styrene sulfonate) and ET (ethylene terephthalate), respectively.

Contact angle. DSA10 contact angle system from KRUSS GmbH was used to measure the surface tension by the sessile drop technique. Two solvents: water (polar), and diiodomethane (unpolar) $\left(2 \mu \mathrm{L}, 25^{\circ} \mathrm{C}, 8 \mathrm{~s}\right)$ were used. The surface tension of polymer $\left(\gamma_{\mathrm{s}}\right)$ was calculated by Young-Dupre and Fowker's equation[26].

Atomic Force Microscopy. Atomic force microscope (AFM) multimode-8 from Bruker was used. AFM scans were carried out in air using Scanasyst probe (ScanAsyst cantilever (Silicon

\footnotetext{
${ }^{1}$ Tanuma, S.; Powell, C. J.; Penn, D. R. Calculation of electron inelastic mean free paths (IMFPs) VII. Reliability of the TPP-2M IMFP predictive equation. Surf. Interface Anal. 2003, 35, 268-275.

${ }^{2}$ Scofield J (1976) Hartree-Slater subshell photoionization cross-sections at 1254 and 1487 eV. J Electron Spectrosc Relat Phenom 8(2):129-37
} 
Nitride), triangular, reflective aluminium, symmetric tip with radius $\leq 10 \mathrm{~nm}, \mathrm{f}_{0}: 70 \mathrm{KHz}$, spring constant: $\sim 0.4 \mathrm{~N} / \mathrm{m}$ ), scan rate $1 \mathrm{~Hz}$, at different scan sizes: $500 \mathrm{~nm} \times 500 \mathrm{~nm}, 2 \mu \mathrm{m} \times 2 \mu \mathrm{m}$ (3 samples). The absolute calibration was performed for each cantilever: Deflection Sensitive, Spring Constant $(\sim 0.4 \mathrm{~N} / \mathrm{m})$ using Thermal Tuning and Lorentzian fitting (air), and Tip Radius by Tip Qualification on Titanium roughness sample for PeakForce QNM (from BRUKER). Samples were dried in vacuum chamber in $4 \mathrm{~h}$ before scanning. Scanning was performed in the room conditions. 3 independent surfaces in the same grafting conditions were analyzed. The roughness $(\mathrm{Ra})$ was measured on 3 points/surface.

Nano-Scope Analysis v.1.5, Image-J and AtomicJ software[27] were used for image analysis. Surface mechanical properties was measured by Peakforce Quantitative Nano-mechanical Properties (PF-QNM) program[28]. When numbers of samples are indicated, they refer to independent experiments (from sample preparation).

\section{Results}

\subsection{Surface characterization}

As a NaSS unit contains one atom of sulfur, the surface density of grafted PNaSS can be estimated based on the percentage of sulfur atoms in the elementary composition using XPS. Sulfur was not detected on the non-grafted-ozonized PET surfaces, but the S2p peak was visible (165 - $170 \mathrm{eV}$ )[29] on the 4 grafted surfaces (see high resolution spectra in Figure S1). The quantification of those contributions indicated that the monomer surface density was much lower in the case of the thermal grafting than for the UV and Mohr's salt catalyzed grafting (Figure $1 \mathrm{~A})$.

Specifically, the S/C ratio for the UV and Mohr's salt samples was more than ten times higher than for thermal grafting (Figure 1A). The PNaSS surface density (SD) by UV irradiation was higher than when using Mohr's salt. The ranking was SDUVG-PET $>S_{\text {MSG-PET }}>S_{\text {TG-PET. }}$. Whilst the XPS confirms the presence of PNaSS, the $\% \mathrm{~S} / \mathrm{C}$ values themselves are small indicating that the layers are thin and most probably patchy. Indeed, a rough estimate value for the UVG PNaSS average layer thickness of $0.05 \mathrm{~nm}$ can be deduced from a simple homogeneous model based on the depth probed by XPS being equal to $10 \mathrm{~nm}$ (Figure S2) and calculations thereafter. 
Nevertheless, the surfaces were more hydrophilic after functionalization (Figure S3) and the surface energy showed some correlation with the XPS results. The surface tension $\left(\gamma_{s}\right)$ of functionalized surfaces was measured by the contact angle method (Figure 1B). Non-grafted and TG-PETs were similar: $\sim 45-48 \mathrm{mN} / \mathrm{m}$. However, surface tension increased significantly on UV grafting samples. Particularly, $\gamma_{\mathrm{s}}$ of UVG-PET increased by $54 \%(73 \mathrm{mN} / \mathrm{m})$ and $8 \%$ for MSG-PET ( $52 \mathrm{mN} / \mathrm{m})$. These variations correlate with the amount of $\mathrm{SO}_{3}{ }^{-}$groups (\% Sulfur by XPS) on the surface leading to the increase of surface tension (represented by the $\mathrm{S} / \mathrm{C}$ ratio in Figure $1 \mathrm{~A})$.
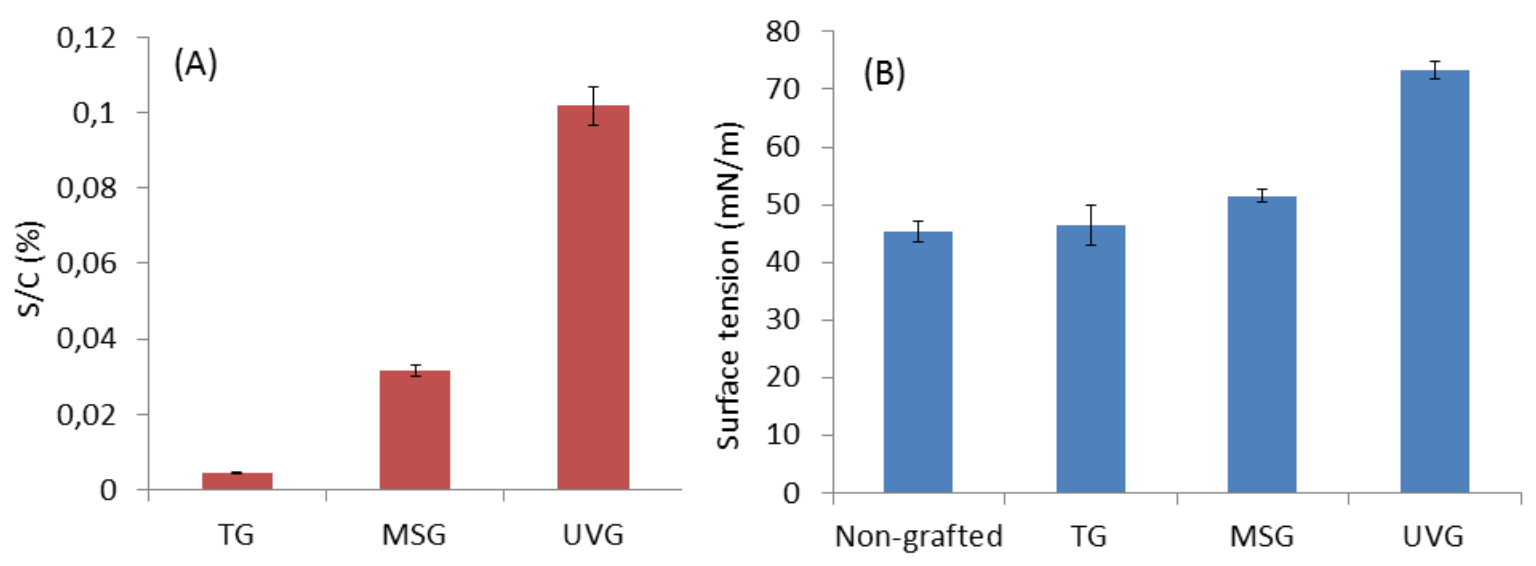

Figure 1. Surface characterization of non-grafted-ozonized and grafted PET: (a) S/C ratio from XPS and (b) surface tension by contact angle

\subsection{Investigating structure of PNaSS-grafted PET surface by AFM}

The surface SEM images showed no obvious changes (Figure S4). Therefore, in this work, we investigated the grafted surface using atomic force microscope (AFM). AFM can be used as a non-destructive method to analyze polymer surfaces[28,30-33]. Numerous parameters can be investigated, e.g. the macromolecule structure[18], thickness[34-39], and adhesion. PNaSS-grafted PET surfaces were investigated by AFM peak force Quantitative Nanomechanical properties (PF-QNM) in air at room temperature and compared to non-graftedozonized surface. Adhesion maps measure the interaction between the AFM tip and the material : they can therefore provide clues as to the local chemical nature of the surface[40]. 
205 The surface topography and adhesion images of non-grafted-ozonized PET were used as a 206 reference. The AFM images of the PET surfaces obtained after PNaSS grafting by the thermal 207 grafting and Mohr's salt grafting methods are shown in Figure 2 and briefly described below.

\section{Thermal radical polymerization:}

209 Thermal grafting. TG-PET surface topography and adhesion were similar to the non-grafted210 ozonized surface (Figure 2A-B). This was in agreement with the XPS and contact angle results 211 which suggested a low degree of grafting. The surface roughness of TG-PET (Ra $=0.76 \mathrm{~nm})$ 212 was similar with that of non-grafted PET $(\mathrm{Ra}=0.96 \mathrm{~nm})$, see in Figure 2E.

213 Thermal grafting in the presence of Mohr's salt. The topography of MSG-PET appeared 214 similar but the surface roughness ( $R a=3.55 \mathrm{~nm}$, see in Figure $2 \mathrm{C}$ ) increased by a factor 3 215 (Figure 2E). 
Height image

(A)

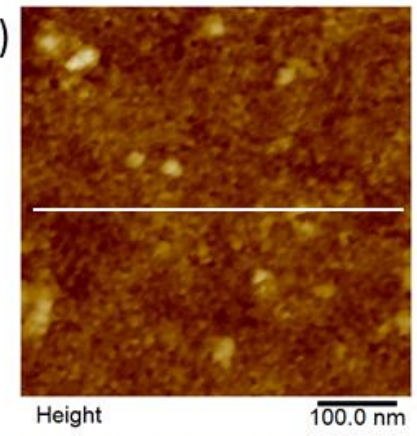

(B)

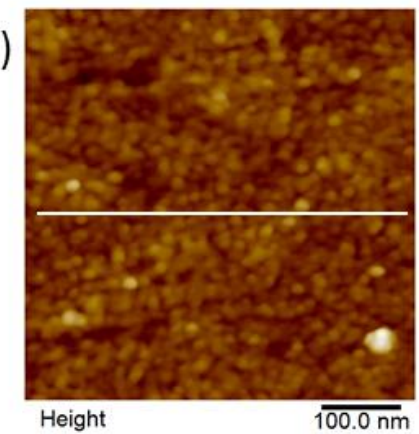

(C)
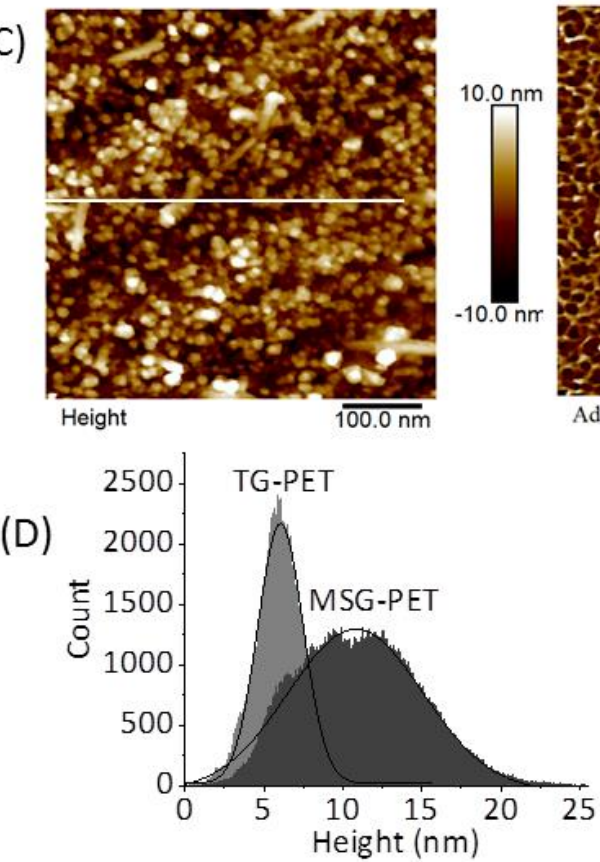
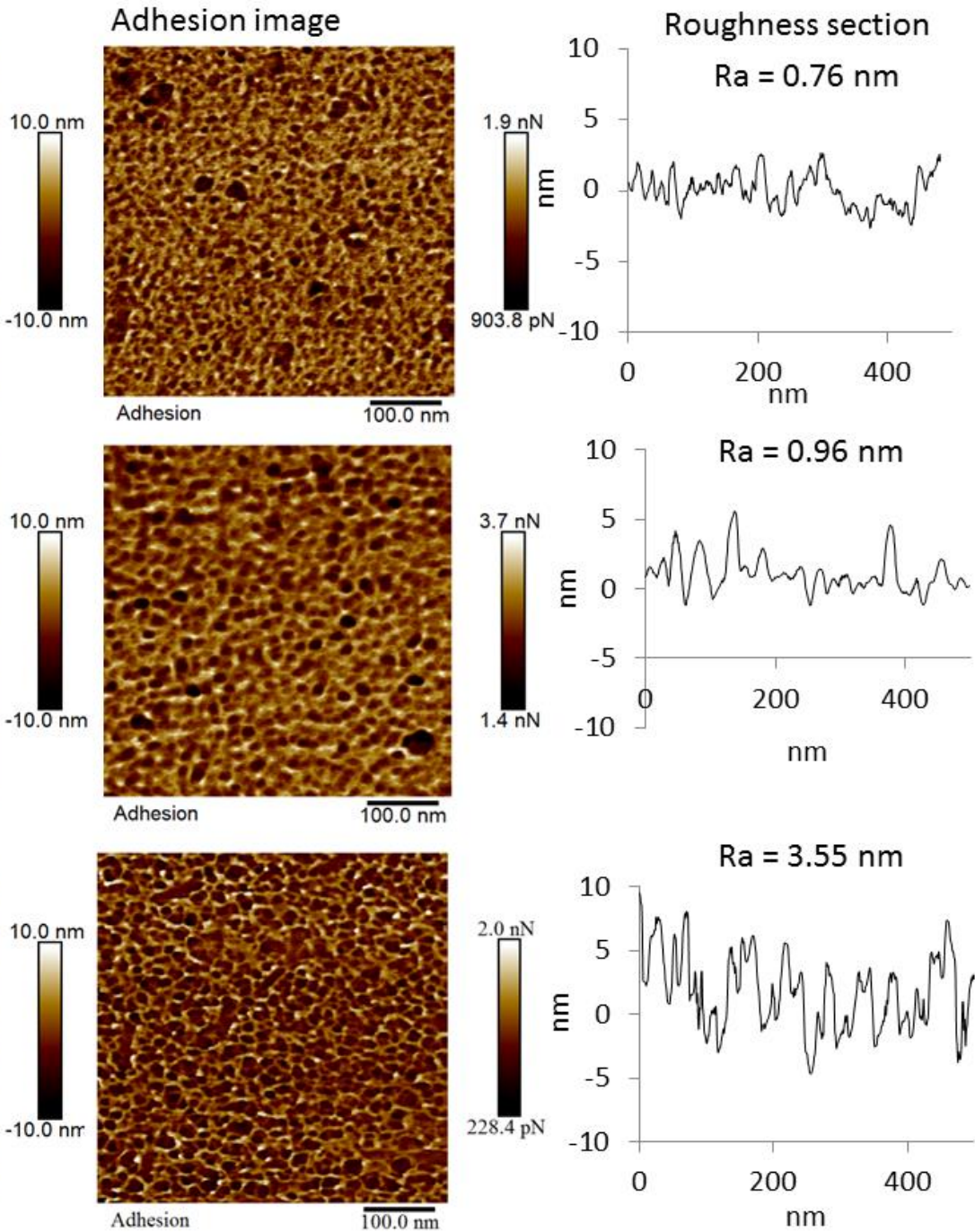

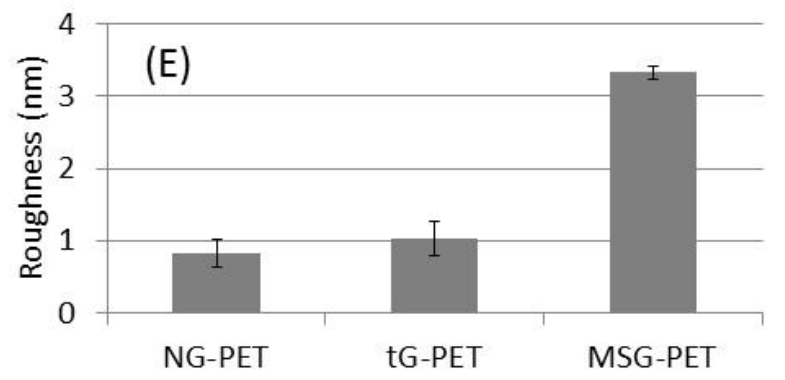

217 Figure 2. AFM images of non-grafted and thermal grafted PET: (A) non-grafted-ozonized PET

218 without grafting, (B) thermal grafting (TG-PET), (C) thermal grafting in the presence of Mohr's

219 salt (MSG-PET), (D) Height distribution of TG-PET and MSG-PET, (E) Roughness values for each 220 method; Scan in air, scan size $500 \mathrm{~nm} \times 500 \mathrm{~nm}, 256$ points/line, scan rate $1 \mathrm{~Hz}$, PF-QNM

Photoinitiated radical polymerization: 
223 UV grafting (UVG). Remarkably, in the case of UV grafting, both topography and adhesion 224 images (Figure 3) were drastically different from what had been observed in the other cases. 225 To evaluate whether the UV treatment itself had an effect on surface topography, a control 226 sample was prepared with non-grafted-ozonized PET under UV irradiation for 30 min without 227 monomer. No major difference between this UV control (Figure $3 A$ ) and the non-grafted228 ozonized control (Figure 2A) were observed. To the contrary, a smoother surface was 229 observed on UV grafted PET with patches particularly striking in the adhesion image (Figure 230 3B). The patch shown in Figure $3 \mathrm{C}$ is $\sim 1.5 \mathrm{~nm}$ thick (red line) and with reduced adhesion 231 (Figure 3D). An average thickness of the patches can be deduced from multiple measurements 232 of different patches ( $1.2 \mathrm{~nm}, \mathrm{n}=5$, Figure S5). Taking into account the surface covered by 233 the patches ( $~ 8 \%$ of the total area, Figure S5) the thickness averaged overall the whole area 234 is $\sim 0.09 \mathrm{~nm}(8 \% \times 1.2 \mathrm{~nm})$, consistent with the XPS results ( 0.05 nm, see above and Figure S2) suggesting that those patches are indeed composed of PNaSS. 
(A) Height

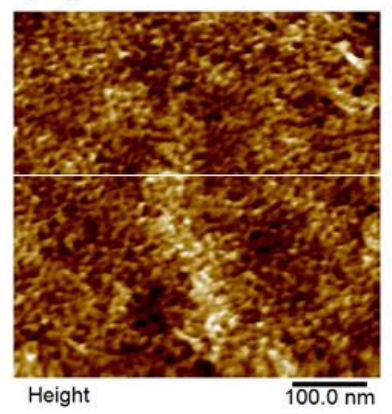

(B)

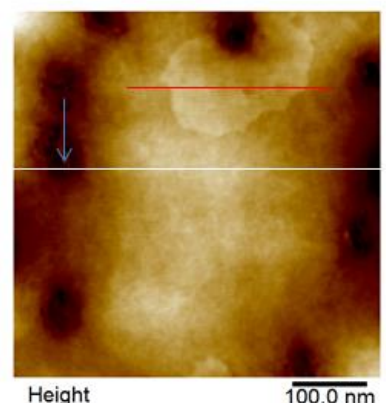

(C)

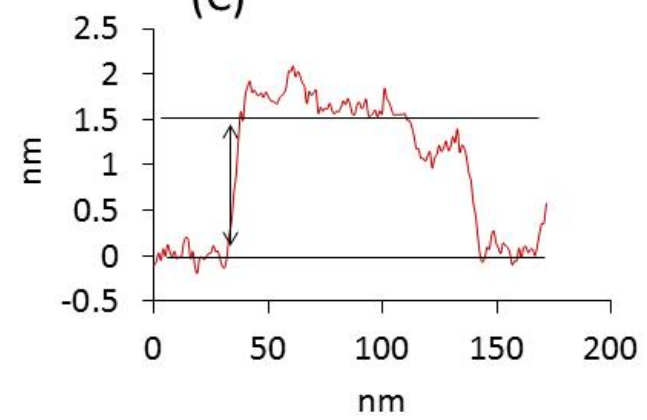

Adhesion

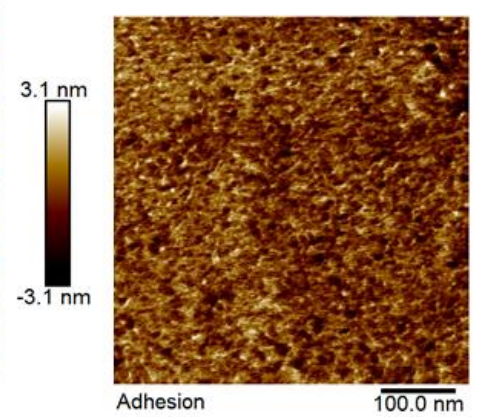

Roughness section

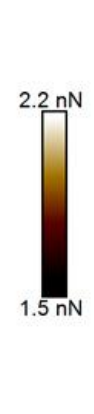

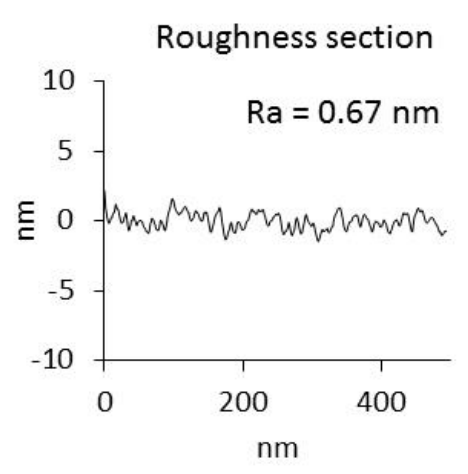
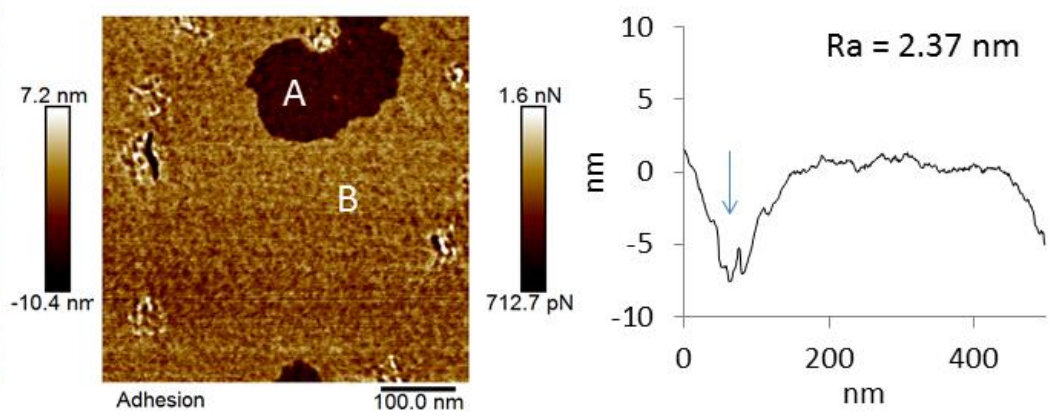

(D)

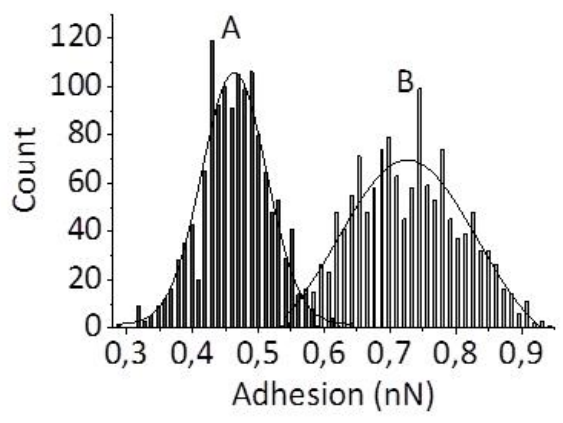

236

237

238

239

240

241

242

243

Figure 3. AFM images of UV grafted PET (A) Control sample (ozonized PET under UV irradiation without monomer), (B) UV grafted PET, (C) Particular Cross-section by red line, and (D) Adhesion force distribution (flat surface, patches); scan size $500 \mathrm{~nm} \times 500 \mathrm{~nm}, 256$ points/line, scan rate $1 \mathrm{~Hz}$, PF-QNM

\section{Discussion}

The combination of the XPS, surface tension and AFM images suggest the following picture of the grafted surfaces. The thermal grafting results indicate a low grafting (XPS results, Figure 1A) on PET. This correlates with the surface tension measurements where we do not observe significant changes from the unmodified surfaces (Figure 1B). The AFM images of those surfaces in dry air may not allow visualization of the PNaSS in the case of thermal grafting. 
The absence of detectable change in the case of thermal grafting is probably due to a combination of low grafting (as indicated by XPS and surface tension) and of the fact that the non-grafted-ozonized PET surface is already rough making it harder to detect small changes. In the case of thermal grafting in the presence of Mohr's salt, XPS and surface tension measurements correlate and both point to an increased functionalization. The AFM images show an increased roughness (Figure 2 and Figure S6) but this increase cannot be attributed to PNaSS because we know from the XPS results that on average the PNaSS layer is only of the order of $\sim 0.02 \mathrm{~nm}$ suggesting a low coverage of thin patches (Figure S2). Instead, the increase of the surface roughness is probably caused by surface degradation in the presence of Mohr's salt redox initiator as previously reported [40]. In the case of photoinitiated radical polymerization (UV grafting), again XPS and surface tension measurements correlate (Figure 1). Compared to Mohr's salt, they point to an increased PNaSS surface density for PET. In the AFM images we observe $\sim 1 \mathrm{~nm}$ thick patches covering $8 \%$ of the surface and with markedly reduced adhesion. We interpret those patches as being PNaSS patches since they correspond to the average thickness estimated by XPS. We note that the rest of the surface show a different (smoother) structure compared to the control. We used an ozonized PET under UV irradiation in distilled water to evaluate if changes to surface topology could have been caused by the UV irradiation treatment but that does not seem to be the case. Further investigations will be needed to determine what causes the smoothening of the PET surface during PNaSS grafting by UV irradiation. Another limitation of our interpretation of the results is that those unexplained topography changes could have contributed to the variations of contact angle independently of PNaSS coverage.

\section{Conclusion}

PNaSS was successfully immobilized by ozonation activation and thermal grafting or UV grafting. The results provide insights into the morphology of PNaSS grafted on polyethylene terephthalate that is commonly used in biomedical engineering by harnessing a combination of AFM-Peakforce Quantitative Nanomechanical properties with XPS and contact angle measurements. Average thicknesses in the nm or sub-nm range determined by XPS indicate a low PNaSS coverage. In the case of UV grafting $1 \mathrm{~nm}$ thick discrete patches covering $8 \%$ of the surface were observed. Some surface reconstruction happening during PNaSS grafting will 
need to be explored in further work. As said in the introduction, the reported findings would allow precising how the pNaSS molecules can interact with specific proteins as fibronectin and by this with cells. A lot of in vitro and in vivo biological results were obtained and published on pNaSS grafted PET and this precise and fine view in the structure of the grafted molecules will be a perfect tool to perfect the elucidation of the mechanism of the biological activity of such surfaces.

\section{Funding Sources}

This work was funded as part of the "Future Investment Project" by the French Public Investment Bank (BPI) and the French state - PSPC application - Liga2bio project.

\section{References}

[1] Felgueiras H P, Sommerfeld S D, Murthy N S, Kohn J and Migonney V 2014 Poly(NaSS) functionalization modulates the conformation of fibronectin and collagen type $i$ to enhance osteoblastic cell attachment onto Ti6Al4V Langmuir 30 9477-83

[2] Vaquette C, Viateau V, Guérard S, Anagnostou F, Manassero M, Castner D G and Migonney V 2013 The effect of polystyrene sodium sulfonate grafting on polyethylene terephthalate artificial ligaments on invitro mineralisation and invivo bone tissue integration Biomaterials 34 7048-63

[3] Curti P S, Moura M R D, Veiga W, Radovanovic E, Rubira A F and Muniz E C 2005 Characterization of PNIPAAm photografted on PET and PS surfaces Appl. Surf. Sci. 245 223-33

[4] Elbert D L, Herbert C B and Hubbell J A 1999 Thin polymer layers formed by polyelectrolyte multilayer techniques on biological surfaces Langmuir 15 5355-62

[5] Girard J, Brunetto P S, Braissant O, Rajacic Z, Khanna N, Landmann R, Daniels A U and Fromm K M 2013 Development of a polystyrene sulfonate/silver nanocomposite with self-healing properties for biomaterial applications Comptes Rendus Chim. 16 550-6

[6] Simoes J A, Citron D M, Aroutcheva A, Anderson R A, Chany C J, Waller D P, Faro S 
and Zaneveld L J D 2002 Two novel vaginal microbicides (polystyrene sulfonate and cellulose sulfate) inhibit Gardnerella vaginalis and anaerobes commonly associated with bacterial vaginosis Antimicrob. Agents Chemother. 46 2692-5

[7] Chouirfa H, Evans M D M, Bean P, Saleh-Mghir A, Crémieux A C, Castner D G, Falentin-Daudré C and Migonney V 2018 Grafting of Bioactive Polymers with Various Architectures: A Versatile Tool for Preparing Antibacterial Infection and Biocompatible Surfaces ACS Appl. Mater. Interfaces 10 1480-91

[8] Chouirfa H, Evans M D M, Castner D G, Bean P, Mercier D, Galtayries A, FalentinDaudré C and Migonney V 2017 Grafting of architecture controlled poly(styrene sodium sulfonate) onto titanium surfaces using bio-adhesive molecules: Surface characterization and biological properties Biointerphases $1202 \mathrm{C} 418$

[9] Harris C M, Miller S G, Andresen K and Thompson L B 2018 Quantitative measurement of sodium polystyrene sulfonate adsorption onto CTAB capped gold nanoparticles reveals hard and soft coronas J. Colloid Interface Sci. 510 39-44

[10] Su N, Li H B, Zheng H M, Yi S P and Liu X H 2012 Synthesis and characterization of poly(sodium-p-styrenesulfonate)/modified SiO 2 spherical brushes Express Polym. Lett. 6 680-6

[11] Moujahid E M, Besse J P and Leroux F 2002 Synthesis and characterization of a polystyrene sulfonate layered double hydroxide nanocomposite. In-situ polymerization vs. polymer incorporation J. Mater. Chem. 12 3324-30

[12] Börner H G, Duran D, Matyjaszewski K, Da Silva M and Sheiko S S 2002 Synthesis of molecular brushes with gradient in grafting density by atom transfer polymerization Macromolecules 35 3387-94

[13] Rohman G, Huot S, Vilas-Boas M, Radu-Bostan G, Castner D G and Migonney V 2015 The grafting of a thin layer of poly(sodium styrene sulfonate) onto poly( $\varepsilon$ caprolactone) surface can enhance fibroblast behavior J. Mater. Sci. Mater. Med. 26 206

[14] Nguyen T N, Rangel A A, Migonney V, Nguyen N T, Rangel A A and Migonney V 2020 Kinetic and degradation reactions of poly (sodium 4-styrene sulfonate) grafting 
[15] Lego B, Skene W G and Giasson J S 2008 Unprecedented covalently attached ATRP initiator onto OH-functionalized mica surfaces Langmuir 24 379-82

[16] Mathis C H, Simič R, Kang C, Ramakrishna S N, Isa L and Spencer N D 2019 Indenting polymer brushes of varying grafting density in a viscous fluid: A gradient approach to understanding fluid confinement Polymer (Guildf). 169 115-23

[17] Ciobanu M, Siove A, Gueguen V, Gamble L J, Castner D G and Migonney V 2006 Radical graft polymerization of styrene sulfonate on poly(ethylene terepthalate) films for ACL applications: "Grafting from" and chemical characterization Biomacromolecules 7 755-60

[18] Yamamoto S, Ejaz M, Tsujii Y and Fukuda T 2000 Surface interaction forces of welldefined, high-density polymer brushes studied by atomic force microscopy. 2. Effect of graft density Macromolecules 33 5608-12

[19] Yamamoto S, Tsujii Y and Fukuda T 2000 Atomic force microscopic study of stretching a single polymer chain in a polymer brush Macromolecules 33 5995-8

[20] Jones D M, Brown A A, Huck W T S, Street P and Cb C 2002 Surface-Initiated Polymerizations in Aqueous Media: Effect of Initiator Density Darren Langmuir 12659

[21] Fujimoto K, Takebayashi Y, Inoue H and Ikada Y 1993 Ozone-induced graft polymerization onto polymer surface J. Polym. Sci. Part A Polym. Chem. 31 1035-43

[22] Amokrane G, Falentin-Daudré C, Ramtani S and Migonney V 2018 A Simple Method to Functionalize PCL Surface by Grafting Bioactive Polymers Using UV Irradiation Irbm $39268-78$

[23] Ishigaki I, Sugo T, Takayama T, Okada T, Okamoto J and Machi S 1982 Graft polymerization of acrylic acid onto polyethylene film by preirradiation method. II. Effects of oxygen at irradiation, storage time after irradiation, mohr's salt, and ethylene dichloride J. Appl. Polym. Sci. 27 1043-51

[24] Fujimoto K, Tadokoro H, Ueda $Y$ and Ikada $Y 1993$ Polyurethane surface modification 
by graft polymerization of acrylamide for reduced protein adsorption and platelet adhesion Biomaterials 14 442-8

[25] Pavon-Djavid G, Gamble L J, Ciobanu M, Gueguen V, Castner D G and Migonney V 2007 Bioactive poly(ethylene terephthalate) fibers and fabrics: Grafting, chemical characterization, and biological assessment Biomacromolecules 8 3317-25

[26] Frederick M. Fowkes and Fowkes F M 1964 Attractive Forces At Interfaces Ind. Eng. Chem. 56 40-52

[27] Hermanowicz P, Sarna M, Burda K and Gabryś H 2014 AtomicJ: An open source software for analysis of force curves Rev. Sci. Instrum. 85

[28] Pittenger B, Erina N, Su C, Mapping M P, Pittenger B, Erina N and Su C 2010 Quantitative Mechanical Property Mapping at the Nanoscale with PeakForce QNM Bruker Appl. Note AN128 AN128 12

[29] Goh S H, Lee S Y, Zhou X and Tan K L 1999 X-ray Photoelectron Spectroscopic Studies of Interactions between Styrenic Polymers and Poly(2,6-dimethyl-1,4-phenylene oxide) Macromolecules 32 942-4

[30] Nair S S, Wang C and Wynne K J 2019 AFM Peakforce QNM mode for measurement of nanosurface mechanical properties of Pt-cured silicones Prog. Org. Coatings 126 $119-28$

[31] Young T J, Monclus M A, Burnett T L, Broughton W R, Ogin S L and Smith P A 2011 The use of the PeakForceTM quantitative nanomechanical mapping AFM-based method for high-resolution Young's modulus measurement of polymers Meas. Sci. Technol. 22

[32] Dokukin M E and Sokolov I 2012 Quantitative mapping of the elastic modulus of soft materials with HarmoniX and PeakForce QNM AFM modes Langmuir 28 16060-71

[33] Kaemmar S B 2011 Introduction to Bruker's ScanAsyst and PeakForce Tapping AFM Technology Appl. note 13312

[34] Sui X, Zapotoczny S, Benetti E M, Schön P and Vancso G J 2010 Characterization and molecular engineering of surface-grafted polymer brushes across the length scales by 
atomic force microscopy J. Mater. Chem. 20 4981-93

393

[35] Chen W L, Cordero R, Tran H and Ober C K 2017 50th Anniversary Perspective: Polymer Brushes: Novel Surfaces for Future Materials Macromolecules 50 4089-113

[36] Halperin A and Zhulina E B 2010 Atomic force microscopy of polymer brushes: Colloidal versus sharp tips Langmuir 26 8933-40

[37] Phillips R W 1994 Atomic force microscopy for thin film analysis Surf. Coatings Technol. 68-69 770-5

[38] Lego B, Skene W G and Giasson S 2010 Swelling study of responsive polyelectrolyte brushes grafted from mica substrates: Effect of $\mathrm{pH}$, salt, and grafting density Macromolecules 43 4384-93

[39] Variola F 2015 Atomic force microscopy in biomaterials surface science Phys. Chem. Chem. Phys. 17 2950-9

[40] Zalakain I, Politakos N, Ramos J A, Saralegi A, Etxeberria H, Mondragon I, Corcuera M A and Eceiza A 2013 Chemical and morphological characterization of sulfonated polystyrene brushes in different environments Eur. Polym. J. 49 2120-7

\section{Declaration of interests}

The authors declare that they have no known competing financial interests or personal relationships that could have appeared to influence the work reported in this paper.

\section{Author Contributions}

Tuan Ngoc Nguyen: principal technical contributor, conception, design and conduct of the experiments, acquisition, analysis, interpretation of data, initial draft the work. Raphaël Lévy: Interpretation of data, draft and substantively revised the work. Vincent Humblot: acquisition, analysis, interpretation of data. Véronique Migonney: supervisor, project conception, draft and substantively revised the work.

All authors have approved the submitted version 